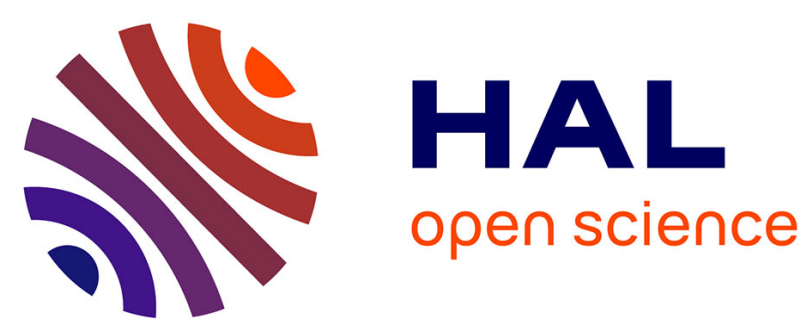

\title{
GaSb-AlSb QUANTUM WELLS. ELABORATION AND OPTICAL PROPERTIES
}

\author{
C. Raisin, L. Lassabatere, P. Voisin, C. Alibert, C. Ance
}

\section{To cite this version:}

C. Raisin, L. Lassabatere, P. Voisin, C. Alibert, C. Ance. GaSb-AlSb QUANTUM WELLS. ELABORATION AND OPTICAL PROPERTIES. Journal de Physique Colloques, 1987, 48 (C5), pp.C5-155C5-158. 10.1051/jphyscol:1987530 . jpa-00226734

\section{HAL Id: jpa-00226734 https://hal.science/jpa-00226734}

Submitted on 1 Jan 1987

HAL is a multi-disciplinary open access archive for the deposit and dissemination of scientific research documents, whether they are published or not. The documents may come from teaching and research institutions in France or abroad, or from public or private research centers.
L'archive ouverte pluridisciplinaire HAL, est destinée au dépôt et à la diffusion de documents scientifiques de niveau recherche, publiés ou non, émanant des établissements d'enseignement et de recherche français ou étrangers, des laboratoires publics ou privés. 
GaSb-AISb QUANTUM WELLS. ELABORATION AND OPTICAL PROPERTIES
C. RAISIN
C. ANCE* *
L, LASSABATERE, P. VOISIN* ,
C. ALIBERT** and

LESIC, Université des Sciences et Techniques du Languedoc, Place Eugene Batailion, F-34060 Montpellier Cedex, France 'Groupe de Phystque des Solides de I'Ecole Normale supérieure, 24, Rue Lhomond, F-75005 Paris, France

* "Equipe Micro-Opto-Electronique de Mpl, Bat. Recherche Phys., Université des Sciences et Techniques du Languedoc. Place Eugène Batailion, F-34060 Montpellier Cedex, France

* "Spectroscopie U.V. des Solides, Université des Sciences et Techniques du Languedoc. Place Eugène Bataillon. F-34060 Montpellier Cedex, France

RESUME

Nous présentons les resultats de caractérisation des surfaces au cours de la préparation et les propriétés optiques d'un puits quantique.

\section{ABSTRACT}

We present the results of surface characterization with respect to the preparation process and some optical properties relevant to the quantum well structure.

INTROOUCTION The mismatch between GaSb and AISb is small $\left(\frac{\Delta_{a} a}{d}=7.10^{-3}\right)$. The interface is strained, but this strain is not too high and therefore the interface quality is good enough to permit interesting studies of the effects induced by the strain. This paper is devoted to a strained GaSb-AlSb single quantum well structure obtained by the confinement of a GaSb layer between two AlSb spacer layer (1). We describe the main features of the elaboration processes and present a study of the low temperature electroreflectance, reflectance and photoluminescence of a single GaSb-AISb quantum well.

ELABORATION. GaSb-AISb QW obtained by confinement of GaSb between two spacer layer of AISD are type I hetero-interfaces system (2). It is necessary to be able to fabricate reproducible high quality interfaces. We have used the Molecular Bean Epitaxy (MBE) growth process and a characterization technique capable of giving details about the quality of an interface. The home-made apparatus used consists of three chambers : a loading chamber, an analysis chamber and a deposition chamber (3). Transportation between chambers is carried out by a magnetically coupled transfer rod. The growth chamber is equiped with a RHEED system and a quadripoiar mass-spectrometer. The analysis chamber allows AES and surface potential measurements 0 by the Kelvin probe (4).

The GaSb (100) substrates were indium-soldered on to the sample holder and chemically polished in a Brome-Methanol solution. Then, they were heated at $580^{\circ} \mathrm{C}$ under $\mathrm{Sb}_{2}$ plus $\mathrm{Sb}_{4}$ flux, under these conditions the oxide film was removed, the surface was clean and presented good RHEED pattern. 
The sample studied consisted of a sustrate with a $1 \mu m$ GaSb buffer layer, and a quantum well grown with the following sequence : a $1000 \&$ thick AlSb barrier, a 90 - 5 \& GaSb well, $200 \&$ AlSb barrier and finally a 90 \& of GaSb passivation layer to prevent oxidation of AlSb. AlSb and GaSb were grown at $560^{\circ} \mathrm{C}$ with flux ratios $V / I I I=3$; the growth rates maintained at $=1 \& / \mathrm{s}$. Under these conditions we observed the same surface reconstruction $(1 \times 3)$ during the growth of GaSb and AlSb layers. (see the fig. 3 insert).

SURFACES AND INTERFACES CHARACTERIZATIONS RESULTS. The growth was initiated onto oxide free smooth GaSb substrate surface Sb depleted ( 0.3 atomic-monolayer) and with residual carbon contamination less than $5.10^{-}$monolayer (fig. lb). The work function (WF) increases because of superficial oxide layer desorption (fig. 2). The growth layer was monitored in situ using RHEED which provided information on both the film smoothness and the surface reconstructions. Spotty bulk - like patterns when the thickness of the layer is in the 20-70 \& range jllustrate the rough growth due to substrate surface roughness (3). No further changes were observed in this pattern, which is characteristic of Ga(Al) stabilized $(1 \times 3)$ and Sb stabilized $(2 \times 3)$ or $\mathrm{c}(2 \times 6)$ surface reconstructions. The work function topographies (T.W.F) are nearly flat (fig. 2), $\Delta \emptyset$ inhomogeneities are smaller than $100 \mathrm{meV}$ on GaSb and AlSb layers. Our TWF measurements indicate that WF (AISb)-WF $(G a S b) \simeq 200 \mathrm{meV}$.
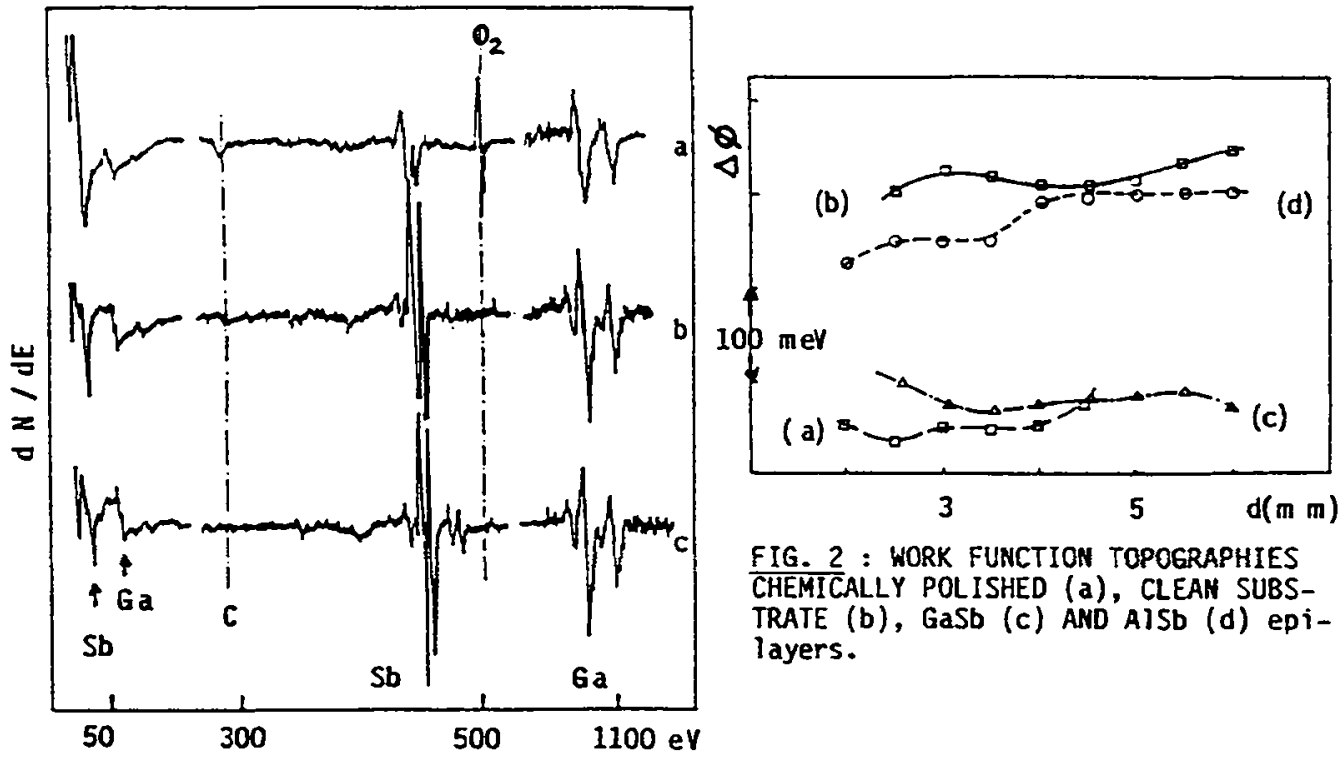

FIG. 2 : WORK FUNCTION TOPOGRAPHIES CHEMICALLY POLISHED (a), CLEAN SUBSTRATE (b), GaSb (c) AND AISb (d) epilayers.

FIGURE I : AES SPECTRA
a) Chemically polished GaSb substrate.
b/ Clean GaSb substrate
c/ GaSb epilayer 
The GaSb-AISb interface is studied during the formation by RHEED. The continuity of the diffraction streaks throughout the entire growth of the quantum well structure indicates the smoothness and abruptness of the hetero-interfaces despite the significant lattice mismatch. The study of physico-chemical and electrical caracteristics of GaSb-AlSb interfaces are reported in this conference (5).

OPTICAL PROPERTIES. The $30 \mathrm{~K}$ electroreflectance (ER) spectrum shown in fig. [3] exhibits several structures. The first one near 831 meV cames from the contribution of the exciton $A_{-}-X$ in GaSb quantum well. Assuming $5 \times 10^{-3}$ for the $\mathcal{E}_{\perp}$ GaSb strain, $40 \mathrm{meV}$ for the heavy hole valence band offset $E_{H H}$ and standard values for the AlSb and GaSb band parameters [6], one obtains using the multi-band envelope function formalism [7] the energies of the main structures of the ER spectrum ( $\mathrm{LH}_{1} \rightarrow \mathrm{E}_{1}=845$ meV, $H H_{1} \rightarrow E_{1}=872 \mathrm{meV}, H H_{2}-E_{2}=1076 \mathrm{meV}, L H_{2} \rightarrow E_{2}=1092 \mathrm{meV}$ and $L H_{1} \rightarrow E_{3}=1.26 \mathrm{eV}$ [8]) Betweeh $0.92 \mathrm{eV}$ and $1 \mathrm{ev}$ a three fold structure appears. In view of its anormalous electric-field dependence and the absence of expected QW transition in this energy, range, this structure seems to be due to the surface quantum well formed by the $90 \AA$ GaSb cap-layer. The three lines of the $2 \mathrm{~K}$ photoluminescence spectra shown in fig (3) are easily identified : at $779 \mathrm{meV}$ the electron-acceptor e-A and at $796 \mathrm{meV}$ the $A-X$ bound exciton recombination in the bulk-like GaSb buffer liyer. At 831 meV the Righ intensity line corresponds certainly to a recombination process within the GaSb QW. From comparison with the electroreflectance data it is clear that the QW luminescence arises from the recombination of exciton bound to shallow defects. The corresponding Stokes shift is $14 \mathrm{meV}$. The linewidth of $=20$ meV results from the broadening and the spreading of the defect binding energies.

FIGURE 3 : ER SPECTRUM $\left(-\frac{1}{\text { PHOTOLUMINESCENCE }}\right.$ AND PHOTOLUMINESCENCE ( $\ldots$ ) , FROM

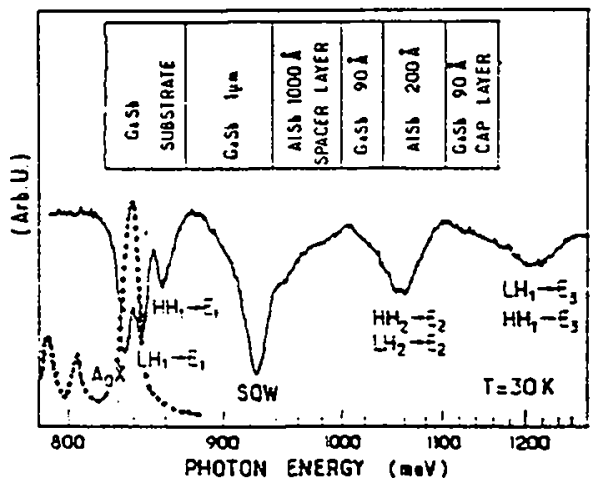

Reflectance spectra has been performed in the 2-5 ev range for various temperatures. Fig. 4 shows the $4 \mathrm{~K}$ reflectance spectra. The reflectance structures correspond to transitions between higher band extrema of the GaSb (bulk, QW and cap-layer) or fundamental and higher extrema of AlSb (1000 \& and $200 \&$ spacers). Energy transitions are obtained using second derivative technique on the reflectance spectra. In the low energy range as in bulk-GaSb the $E$, transition occurs at 2.18 eV

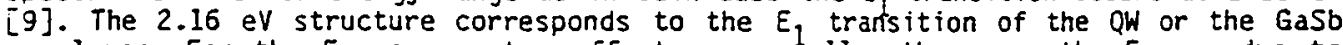
cap-layer. For the $E$ gap quantum effects are shaller than near the $E$ gap due to lower energy barriers and higher effective masses [10]. So the observed $20 \mathrm{meV}$ red shift arises primarly from the strain which lowers the $E_{1}$ gas of the $Q W$ or GaSb cap-layer. The reflectance spectra also shows the $E_{1}+\Lambda$ gap of GaSb at $2.6 \mathrm{eV}$, the $E_{1}(2.94 \mathrm{eV}), E_{1}+\Lambda_{1}(3.35 \mathrm{eV})$ gap of AlSb. The structure near4.4 $\mathrm{aV}$ corresponds to the $E_{2}$ edge of GaSb and AlSb. All these energies transitions are in agreement with bulk-values $[9,11,12,13]$. 


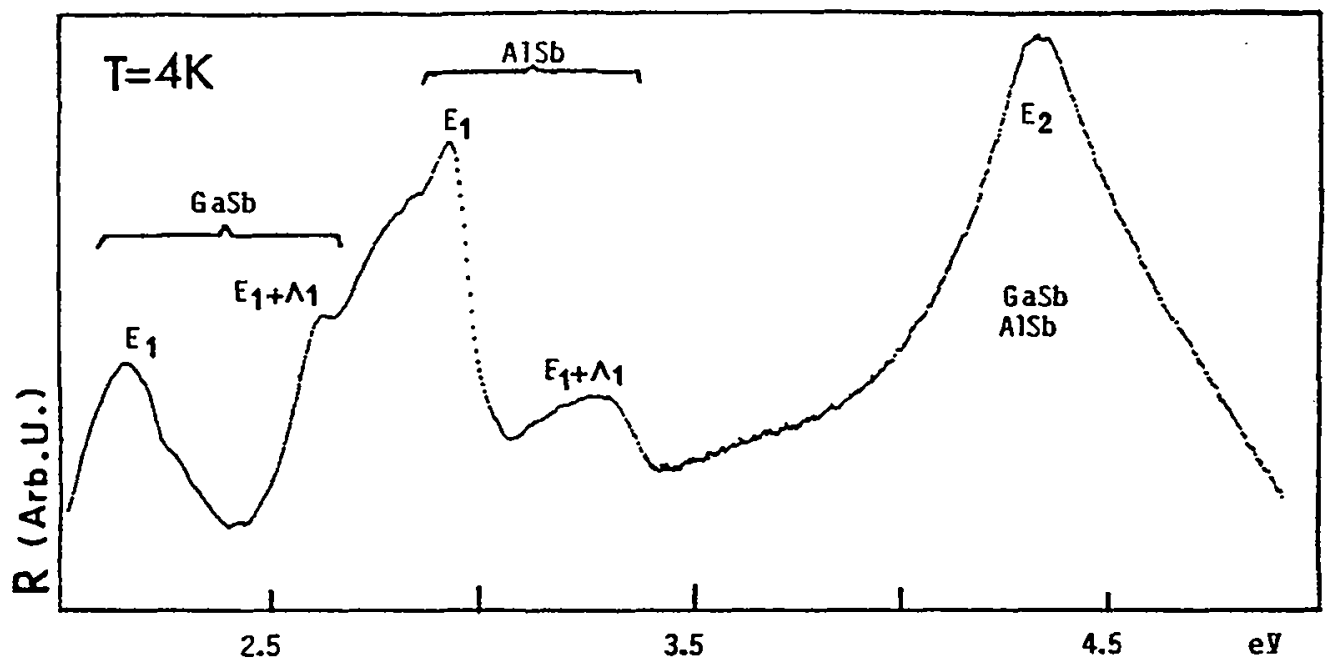

FIGURE 4: REFLECTANCE FROM GASb-AISb QW STRUCTURE.

CONCLUSION. A high quality GaSb-AISb QW structure has been grown. The quality and properties of surfaces and interfaces has been characterized with respect to the elaboration process. These structures present nice electroreflectance, reflectance and photoluminescence properties, the analysis of which can be correlated to confinement energy effect and to the plastic relaxation of ATSD spacer and strained GaSb layer, consistent with mean features of the structure.

Acknowledgements : LESIC (U.A. 787), GPS-ENS (U.A. 392), EM² (U.A. 17) and Spectroscopie U.V. des Solides (U.A. 790) are "Unités Associees au CENTRE NATIONAL DE LA RECHERCHE SCIENTIFIQUE".

[1] P. VOISIN, Surf. SCi. 168, 546, 1986 and P. VOISIN, C. DELALANDE, G. BASTARD, M. VOOS, L.L. CHANG, A. SEGMULLLR, C.A. CHANG and L. ESAKI, Superlattices Microstructures 1, 155, 1985.

[2] L. ESAKI, Molecular Bean Epitaxy and Heterostructures, L.L. CHANG, K. PLOOG Ed ; Mart inus Nijhoff Publishers, 1985.

[3] C. RAISIN, B. SAGUINTAAH, H. TEGMOUSSE, L. LASSABATERE, B. GIRAULT, and C. ALIBERT, Ann. Telecommun. 4i, 50, 1986.

[4] L. LASSABATERE, J.M. PALAU, E. VIEUJOT-TESTEMALE, A. ISMAIL, C. RAISIN, J. BONNET and L. SOONCKINDT, J. VaC. SCi. Technol. B1, 540, 1983.

[5] C. RAISIN, H. TEGMOISSE and L. LASSAPATERE, Formation and properties of MBE grown AlSb-GaSb (100) interfaces (in this conference).

[6] LANOOLT-BORNSTEIN, Numerical data and functional relationships in science and technology, edited by 0 . MADELUNG, Group III, vol. 17. (Springer-Verlag, 1982).

[7] J.Y. MARZIN, in "Heterojunctions and semiconductor superlattices", edited by G. ALLAN, G. BASTARD. M. LANNOO and M. VOOS (Springer-Verlag, 1986), P. 161 ; J.Y. MARZIN and P. VOISIN, unpublished.

[8] C. RAISIN, L. LASSABATERE, C. ALIBERT, B. GIRAULT, G. ABOEL-FATTAH and, P. VOISIN. Solid State Corm ; 61, 17, 1987.

[9] C. ALIBERT, A. JOULLIE, A.i4. jOULLIE and C. ANCE, Phys. Rev. 827, 4946, (1983).

[10] M. ERMAN, J.B. THEETEN, P. FRI UL:NK, S. GAILLARD, F.J. HUA and C. ALIBERT. Journal of Applied Phys. 56, 3241 (1984).

[11] A. JOULLIE, B. GIRAULT, A. M. JOULLIE and A. ZEIN-EDOINE.

Phys. Rev. B 25, 7830, (1982).

[12] D.E. ASPNES, C.G. OLSOM and D.A. IYNCH

Phys. Rev. B14, 4450, (1976).

[13] M. CARDONA, K.L. SHAKLEE and F.H. POLLAK. Phys. Rev. 154, 696 (1967). 